\title{
Scrub Typhus Encephalitis: A Case Series from West Bengal
}

\author{
Rudrajit Paul ${ }^{1}$, Indranil Thakur ${ }^{2}$
}

\begin{abstract}
Scrub typhus is an emerging infectious disease in India. The disease can have varied presentations. Recently, during the rainy season, scrub typhus has emerged as one of the main etiologies of febrile illness in West Bengal. We here report four cases of encephalitis caused by scrub typhus. The varied presentations and laboratory features of the patients have been discussed in detail.

Keywords: Doxycycline, Encephalitis, Scrub typhus, Seizures, Serology.

Bengal Physician Journal (2019): 10.5005/jp-journals-10070-6117
\end{abstract}

\section{INTRODUCTION}

Scrub typhus is a vector-borne zoonotic infectious disease caused by Orientia tsutsugamushi, an intracellular rickettsia. ${ }^{1}$ The disease is carried by the larvae of mites (Trombiculidae family), and persons exposed to undergrowth or agricultural fields infested with the mites are at risk of developing the disease. ${ }^{1}$ The disease can be an occupational risk for farmers, forest workers, soldiers, or spelunkers.' Mortality can be up to $50 \%$ in some cases.' Different parts of India are increasingly reporting the incidence of this infection. ${ }^{2}$

Scrub typhus is an emerging infectious disease in India. The disease was first reported from South India in 2009.' But now, most states of India have reported the disease. ${ }^{2}$ Clinical presentation of scrub typhus can be varied, and involvement of almost all systems and organs has been documented, either singly or in combination. ${ }^{2}$ The low index of suspicion among clinicians often leads to delay in diagnosis, and this increases mortality considerably.

In the current (2019) year, during the monsoon and postmonsoon seasons, a number of cases of scrub typhus have been reported from various parts of West Bengal. The symptomology was often protean, and clinicians were baffled by the myriad presentations of the infection. The disease was reported from both urban and rural areas. In a sizeable number of cases, encephalopathy was the presenting symptom along with fever. We here report a few of such cases (Table 1).

\section{Case Description}

\section{CASE 1}

This was an 18-year-old female, presenting with high fever and headache for 5 days, and focal seizures starting 2 days after the onset of fever. She was brought to the ER in an unconscious state, and at presentation, the Glasgow coma scale (GCS) score was 8/15 with bilaterally extensor plantar. Computed tomography (CT) scan of the brain was normal, and the cerebrospinal fluid (CSF) study revealed 260 cells $/ \mathrm{mm}^{3}$ (95\% lymphocytes), protein $68 \mathrm{mg} / \mathrm{dL}$, sugar $65 \mathrm{mg} / \mathrm{dL}$. Liver and kidney function tests were normal. Total leukocyte count was $6,800 / \mathrm{mm}^{3}$, and the platelet count was $2.3 \mathrm{~L} / \mathrm{\mu L}$. Procalcitonin level was 0.056 . The patient recovered after IV doxycycline.

\section{Case 2}

A 27-year-old female presented with high-grade continuous fever for 12 days and generalized convulsions for 2 days. MRI brain was
${ }^{1}$ Department of Critical Care Medicine, Institute of Post Graduate Medical Education and Research and Seth Sukhlal Karnani Memorial Hospital, Kolkata, West Bengal, India; Expert Group on Encephalitis, Government of West Bengal, West Bengal, India

${ }^{2}$ Department of Critical Care Medicine, Institute of Post Graduate Medical Education and Research and Seth Sukhlal Karnani Memorial Hospital, Kolkata, West Bengal, India

Corresponding Author: Rudrajit Paul, Department of Critical Care Unit, Institute of Post Graduate Medical Education and Research and Seth Sukhlal Karnani Memorial Hospital, Kolkata, West Bengal, India, Phone: +91 9433824341, e-mail: r.paul.medicalcollege@gmail.com

How to cite this article: Paul R, Thakur I. Scrub Typhus Encephalitis: A Case Series from West Bengal. Bengal Physician Journal 2019;6(2): 33-35.

Source of support: Nil

Conflict of interest: None

normal, but CSF could not be done due to severe restlessness. Kidney function test was normal, but liver function test showed SGOT/ PT: 237/216 IU/L and alkaline phosphatase (ALP) 580 IU/L. Serum bilirubin was normal, as was kidney function. After positive scrub typhus serology detection, the patient recovered with doxycycline. Liver function test became normal after 1 week.

\section{Case 3}

A 40-year-old male from Hooghly, West Bengal came with highgrade fever for 4 days and altered behavior for 2 days. The patient had headache and vomiting, followed by drowsiness. At admission, opsoclonus-myoclonus was found. There was terminal neck rigidity. Total leukocyte count was $22,500 / \mathrm{mm}^{3}$ with $80 \%$ neutrophils, and platelet count was $2.1 \mathrm{~L} / \mathrm{mm}^{3}$. Blood urea/creatinine was $61 / 2.4 \mathrm{mg} / \mathrm{dL}$, increasing to $58 / 3.1 \mathrm{mg} / \mathrm{dL}$ of day 3 , before resolving. CSF study revealed $1-2$ cells $/ \mathrm{mm}^{3}$, glucose $56 \mathrm{mg} / \mathrm{dL}$ and protein $121 \mathrm{mg} / \mathrm{dL}$. The patient was empirically started on IV acyclovir and doxycycline. Later, blood for scrub typhus IgM came positive, while CSF for herpes simplex virus (HSV) PCR was negative. Serum glutamic oxaloacetate transaminase (SGOT) and serum glutamic pyruvate transaminase (SGPT) increased to 78 and $82 \mathrm{IU} / \mathrm{L}$, respectively, before resolving. Procalcitonin was $<0.02$. The fever subsided, and consciousness became normal with doxycycline. But, the opsoclonus and slightly altered behavior persisted for 2 weeks. MRI brain was normal.

(c) The Author(s). 2019 Open Access This article is distributed under the terms of the Creative Commons Attribution 4.0 International License (https://creativecommons. org/licenses/by-nc/4.0/), which permits unrestricted use, distribution, and non-commercial reproduction in any medium, provided you give appropriate credit to the original author(s) and the source, provide a link to the Creative Commons license, and indicate if changes were made. The Creative Commons Public Domain Dedication waiver (http://creativecommons.org/publicdomain/zero/1.0/) applies to the data made available in this article, unless otherwise stated. 
Scrub Typhus Encephalitis: A Case Series from West Bengal

Table 1: Presenting features of the four patients

\begin{tabular}{lllll}
\hline Presenting features & Case 1 & Case 2 & Case 3 & Case 4 \\
\hline Age & 18 & 27 & 40 & 20 \\
Neurological signs & Focal seizure & Generalized seizures & Severe headache & Terminal neck rigidity \\
& $\begin{array}{l}\text { Neck rigidity } \\
\text { Bilateral extensor plantar }\end{array}$ & & Terminal neck rigidity & \\
Highest TLC & 6,800 & 12,000 & Opsoclonus-myoclonus & 15,800 \\
Highest creatinine & 0.8 & 0.5 & 22,500 & 1.5 \\
Highest SGOT & 21 & 237 & 3.1 & 176 \\
Highest SGPT & 26 & 216 & 78 & 170 \\
Any other feature & - & - & 82 & Eltered behavior \\
& & & & edema \\
\hline
\end{tabular}

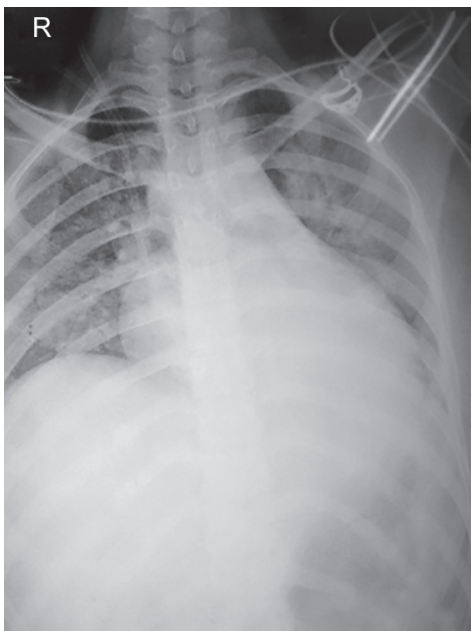

Fig. 1: Chest X-ray of Case 4 showing early pulmonary edema and mild cardiomegaly

\section{Case 4}

A 20-year-old female was admitted with high-grade fever for 7 days and unconsciousness for 2 days. There was terminal neck rigidity, and CT scan of the brain was normal. CSF study revealed a cell count of $20 / \mathrm{mm}^{3}$, all lymphocytes protein $141 \mathrm{mg} / \mathrm{dL}$, and sugar $35 \mathrm{mg} / \mathrm{dL}$. Urea/creatinine was $49 / 1.1 \mathrm{mg} / \mathrm{dL}$ at presentation, increasing to $51 / 1.5$ on day 2 , before settling. In the liver function test, bilirubin was normal, but SGOT/PT were 176/170 IU/L, respectively. International normalized ratio (INR) was 0.88 . Total leukocyte count was $15,800 / \mathrm{mm}^{3}$ (N: 70\%), and platelet count was $1 \mathrm{~L} / \mathrm{mm}^{3}$. In this case, the patient had hypotension (B.P.: $90 / 60 \mathrm{~mm} \mathrm{Hg}$ ) for the first 3 days and also complained of some dyspnea (after regaining consciousness on day 2 ). Chest X-ray (Fig. 1) revealed early pulmonary edema. Echocardiography showed slightly reduced left ventricular systolic function (EF: 50\%). However, the blood serology for scrub typhus was positive, and all symptoms resolved with doxycycline oral therapy.

All the serological tests for scrub typhus were done from the School of Tropical Medicine, Kolkata. In none of the four cases, any eschar was discovered. Other etiologies of encephalitis like Jap B, leptospira, dengue, and malaria were ruled out in all patients by suitable tests (to rule out double infection).

\section{Discussion}

Every year, during the monsoon season and afterward, acute encephalitis syndrome (AES) emerges as an epidemic in different pockets of India. ${ }^{3}$ Usually, the major number of cases is reported from a few states like Uttar Pradesh, West Bengal, Assam, and Tripura. ${ }^{3}$ Acute encephalitis is a medical emergency, especially in children and physicians must decide on a proper treatment algorithm quickly. However, the etiology of AES is varied, and often there is much confusion as to the suitable protocol for management. Japanese encephalitis B is an important cause of $A E S$, but the proportion of $A E S$ cases due to Jap $B$ is slowly reducing in India due to immunization and better vector control. In such a situation, scrub typhus is emerging as an important cause of AES.

A study from UP, India stated that more than $60 \%$ of AES cases were positive for scrub typhus IgM. ${ }^{4}$ The case fatality rate was 1 in $6 .{ }^{4}$ In another study from Assam, out of the AES cases, 1 in 5 was scrub typhus. ${ }^{3}$ Similar reports have also been published from other ends of India. ${ }^{3}$ In the study from Assam, the absence of eschar often led to pushing scrub typhus lower down the list of differential diagnoses, and thus, delays in diagnosis. ${ }^{5}$ In our present series too, none of the four patients had any eschar. Thus, a high index of suspicion is necessary for endemic zones to facilitate early diagnosis of scrub typhus. In this same study, Khan et al. found the common presenting symptoms of scrub typhus to be fever, altered sensorium, headache, and nausea. ${ }^{5}$ Neck rigidity was present in less than $1 \%$ of cases. But in the present series, terminal neck rigidity was found in $75 \%$ of the cases (Table 1). Also, in Assam study, it was found that $49 \%$ of the patients died after discharge. The cause of this high mortality has not been analyzed. Therefore, it may be a good practice to complete at least a sizeable portion of the treatment before discharging scrub typhus cases. Selecting the proper drug is of paramount importance too. In UP, azithromycin has been recommended as a first-line treatment for scrub typhus since $2014 .^{3}$ But that failed to reduce mortality of scrub typhus encephalitis, probably because azithromycin does not penetrate the CNS. These pharmacodynamics considerations must be taken into account.

In India, there are various etiologies of AES, including West Nile virus, Japanese encephalitis $B$, and dengue. These diseases occur in the same geographical locations during the same monsoon, postmonsoon periods and often have similar presentations. Moreover, one person can be infected with multiple pathogens. Hence, physicians dealing with such patients should be sure to complete a comprehensive array of diagnostic tests. Also, these diseases may occur throughout the year. Hence, out-of-season cases should also be considered ineligible patients.

The exact pathophysiology of encephalitis in this infection is unknown. Probable mechanisms include vasculitis of small vessels, especially in the grey matter of the brain. ${ }^{6}$ Pathologic findings include histiocytes, lymphocytes, and plasma cell infiltration of the leptomeninges, typhus nodules, and brain hemorrhage. ${ }^{6}$ 
Usually, the neurological symptoms and signs in scrub typhus encephalitis resolve completely, after therapy and only rarely, there are sequelae like prolonged coma or quadriparesis. ${ }^{7}$ All four of our cases recovered completely without any neurological sequelae. One of our cases had the rare manifestation of opsoclonus (case 3 ). This is an extremely rare manifestation, and in a study from CMC, Vellore, it was reported in $1 \%$ of cases. ${ }^{8}$ The opsoclonus usually resolves after treatment. ${ }^{8}$

Scrub typhus is a multisystem disease, and thus besides encephalitis, other systemic manifestations can also be found. ${ }^{9}$ In our cases, some of the patients had transaminitis and acute kidney injury. One patient had pulmonary edema. They all recovered with treatment. In a study on scrub typhus from Shillong, India, altered liver function test, acute kidney injury (AKI), and pulmonary edema were described in 100,38 , and $23 \%$ of the cases, respectively. Thus, encephalitis, along with other systemic features should prompt physicians to rule out scrub typhus.

\section{Conclusion}

We present these cases to sensitize clinicians to such cases of scrub typhus encephalitis. The public health programs on AES in India should also include this disease in the list of first-line investigations.

\section{Acknowledgment}

Prof Asutosh Ghosh, Head, Department of Critical Care Medicine, IPGMER.

\section{References}

1. Takhar RP, Bunkar ML, Arya S, et al. Scrub typhus: A prospective, observational study during an outbreak in Rajasthan, India. Natl Med J India 2017;30(2):69-72.

2. Sharma N, Biswal M, Kumar A, et al. Scrub Typhus in a Tertiary Care Hospital in North India. Am J Trop Med Hyg 2016;95(2):447-451. DOI: 10.4269/ajtmh.16-0086.

3. Murhekar MV. Acute Encephalitis Syndrome and Scrub Typhus in India. Emerg Infect Dis 2017;23(8):1434. DOI: 10.3201/eid2308.162028.

4. Murhekar MV, Mittal M, Prakash JA, et al. Acute encephalitis syndrome in Gorakhpur, Uttar Pradesh, India - Role of scrub typhus. J Infect 2016;73(6):623-626. DOI: 10.1016/j.jinf.2016.08.014.

5. Khan SA, Bora T, Laskar B, et al. Scrub typhus leading to acute encephalitis syndrome, Assam, India. Emerg Infect Dis 2017;23(1): 148-150. DOI: 10.3201/eid2301.161038.

6. Heo YJ, Jeong HW. Uncommon Manifestations of Scrub Typhus Encephalitis in Two Cases: Clinical and Magnetic Resonance Imaging Findings. J Korean Soc Radiol 2015;73(5):337-342. DOI: 10.3348/ jksr.2015.73.5.337.

7. Huang $M$, Juan $Y$, Chen $Y$. Prolonged coma in a scrub typhus patient. Int J Infect Dis 2018;77:5-7. DOI: 10.1016/j.ijid.2018.09.015.

8. Ralph R, Prabhakar AT, Sathyendra S, et al. Scrub typhus-associated opsoclonus: Clinical course and longitudinal outcomes in an Indian cohort. Ann Indian Acad Neurol 2019;22(2):153-158. DOI: 10.4103/ aian.AIAN_198_18.

9. Jamil MD, Hussain $M$, Lyngdoh $M$, et al. Scrub typhus meningoencephalitis, a diagnostic challenge for clinicians: A hospital based study from North-East India. J Neurosci Rural Pract 2015;6(4):488-493. DOI: 10.4103/0976-3147.169769. 